\title{
A Method of Isolating Anucleated Yeast Protoplasts Unable to Synthesize the Glucan Fibrillar Component of the Wall
}

\author{
By MARIE KOPECKÁ, M. GABRIEL AND O. NEČAS \\ Department of General Biology, Faculty of Medicine, \\ J. E. Purkyně University, Brno, Czechoslovakia
}

(Received 26 July 1973; revised 2 October 1973)

\section{SUMMAR Y}

\begin{abstract}
A mixture of nucleated and anucleated protoplasts was produced from logphase Saccharomyces cerevisiae by the use of snail enzymes. The mixture was separated by centrifugation, and anucleated protoplasts were studied by means of light and electron microscopy. Anucleated protoplasts did not synthesize glucan fibrils even though they seemed to contain all other basic structures in their cytoplasm, and the structure of the plasma membrane was unchanged. This was in sharp contrast to ordinary nucleated protoplasts which synthesized glucan fibrils even after inhibition of protein synthesis by cycloheximide. The reason for this behaviour of anucleated protoplasts is not clear. Such anucleated yeast protoplasts represent the first example of uniform anucleated fungi produced by a reproducible method.
\end{abstract}

\section{INTRODUCTION}

The protoplasts of Saccharomyces cerevisiae cultivated in liquid media produced only an incomplete wall of a fibrillar appearance (Kopecká, Čtvrtníček \& Nečas, I965; Nečas, I965) which was composed of linear and branched $\beta(I \rightarrow 3)$ glucan (D. R. Kreger and M. Kopecká, unpublished data) and seemed to be analogous to the fibrillar component of the yeast wall (M. Kopecká, H. J. Phaff and G. Fleet, unpublished data).

It has been reported by several authors that biosynthesis of the fibrillar glucan component in protoplasts can be blocked. For example, the fibrillar component was not formed in the absence of glucose in the medium (Kopecká, Nečas \& Svoboda, I968) or in the presence of 2-deoxy-D-glucose (Farkaš, Svoboda \& Bauer, I969). In both instances the synthesis of glucan was apparently inhibited at the level of synthesis of sugar nucleotide(s). Other authors have reported that after inhibition of protein synthesis by cycloheximide, the synthesis of the glucan fibrillar component of yeast protoplasts continued unaffected (Nečas, Svoboda \& Kopecká, 1968). These results led to the hypothesis that synthesis of glucan macromolecules, their subsequent transport* and their assembly into fibrils are independent of protein synthesis. The glucan synthetases are believed to be enzymes of a relatively low turnover. If this hypothesis is correct then all phases of glucan fibril biosynthesis should also occur in anucleated yeast protoplasts. The aim of the experiments described was to find out whether anucleated protoplasts possessed the ability to synthesize the glucan fibrils. Conclusive evidence was obtained that anucleated yeast protoplasts were incapable of synthesizing the fibrillar glucan component of the wall.

\footnotetext{
* Only believed by O.N.
} 


\section{METHODS}

Strain. Saccharomyces cerevisiae strain no. 7 was used throughout the experiments.

Preparation of protoplasts. Yeasts from the stock culture were inoculated into $50 \mathrm{ml}$ malt extract medium of $\mathrm{pH} 5.5$ and incubated at $28{ }^{\circ} \mathrm{C}$. After $24 \mathrm{~h}$ all yeasts were transferred to $2000 \mathrm{ml}$ malt extract medium and shaken at room temperature. After approximately $\mathrm{I} 2 \mathrm{~h}$ of cultivation at room temperature, yeasts were near the end of the log phase (Fig. I) and were used for the preparation of protoplasts. The yeasts were centrifuged for $5 \mathrm{~min}$ at $670 \mathrm{~g}$ and washed three times with distilled water. A $200 \mathrm{~m}$ portion of $2 \%$ snail enzymes dissolved in osmotic stabilizer ( $0.6 \mathrm{M}-\mathrm{KCl}$ in McIllvaine citrate-phosphate buffer, $\mathrm{pH} 5.5$ ) was added to the yeast pellet (about $40 \mathrm{~g}$ wet wt). After 2 to $3 \mathrm{~h}$ of shaking at $28{ }^{\circ} \mathrm{C}$ almost all yeasts were converted to protoplasts. The suspension of protoplasts was a mixture of large nucleated protoplasts and small anucleated ones. Centrifugation for $6 \mathrm{~min}$ at $670 \mathrm{~g}$ was used to separate large nucleated protoplasts from small anucleated ones. The large protoplasts were in the pellet and the small ones in the supernatant. The supernatant containing the small protoplasts was decanted, centrifuged for $10 \mathrm{~min}$ at $670 \mathrm{~g}$, then washed three times by centrifugation with osmotic stabilizer to remove the snail enzymes completely. The final yield of small protoplasts was approximately $0.5 \mathrm{~g}$ wet wt (i.e. about $\mathrm{I} \%$ of the initial weight of all yeasts). Three batches of protoplasts were prepared with the same yield of anucleated protoplasts. The large protoplasts ( $2 \mathrm{~g}$ wet wt) were also washed in osmotic stabilizer by centrifugation for $6 \mathrm{~min}$ at $670 \mathrm{~g}$.

Nuclear staining. Nuclei were stained for light microscopy observations according to a modified Giemsa method (Macy \& Miller, 1971).

Cultivation of protoplasts. Protoplasts were cultivated either in liquid media (NI according to Nečas (1965), and malt extract with $0.6 \mathrm{M}-\mathrm{KCl}$ ) or on the surface of $2 \%$ agar $\mathrm{NI}$ medium. Protoplasts were observed using a phase-contrast microscope.

Electron microscopy. Formation of glucan fibrils was examined in preparations of protoplasts shadowed with carbon and platinum. Protoplasts were collected after $24 \mathrm{~h}$ and 5 days of cultivation in liquid media. A drop of the culture medium containing living protoplasts was placed on a copper grid covered by a Formvar supporting-film. Protoplasts were applied to the grid and the preparation was left to dry. A drop of distilled water was then placed on the grid and removed after Io min. This was repeated two or three times. After drying, the preparations were shadowed with carbon and platinum. The numbers of protoplasts which had and had not the fibrillar component on the surface were counted by electron microscopy.

The ultrastructure of protoplasts was observed on freeze-etching replicas. Anucleated protoplasts were placed on copper grids, either directly in snail enzymes or in liquid nutrient medium, and frozen in Freon 22 cooled by liquid nitrogen. Freeze-etching was performed by means of Balzer's apparatus (Moor \& Mühlethaler, 1963).

Protoplasts for ultra-thin sectioning were fixed in $3 \%$ glutaraldehyde with $0.65 \mathrm{M}$ mannitol in phosphate buffer $\left(\mathrm{pH}_{7} \cdot 0\right.$ ) for $24 \mathrm{~h}$ (and postfixed in $\mathrm{I} \% \mathrm{OsO}_{4}$ ) or fixed in $\mathrm{I} \cdot 5 \% \mathrm{KMnO}_{4}$ with $0.65 \mathrm{M}-\mathrm{KCl}$ for $2 \mathrm{~h}$.

Size of protoplasts. This was measured with an eyepiece micrometer by light-microscopy, on electron micrographs of ultra-thin sections and on freeze-etching replicas. 
RESULTS

\section{Isolation of anucleated protoplasts}

At the end of the exponential phase of growth anucleated protoplasts of Saccharomyces cerevisiae were prepared as described above. These yeasts represented an asynchronous population in which there were both non-budding cells and budding yeasts with buds of different sizes (Fig. I). In the snail-enzyme solution the first protoplasts appeared after 5 to Io min and most of them were much smaller than those produced from mature yeasts. After 2 to $3 \mathrm{~h}$ further incubation the number of protoplasts increased until almost all cells were converted into protoplasts of two different sizes (Fig. 2). The small protoplasts had an average diameter of $2 \cdot 2 \mu \mathrm{m}$ and the large ones were about $6 \mu \mathrm{m}$. Almost all large protoplasts (Fig. 3) were nucleated while the small protoplasts (Fig. 4) were anucleated.

\section{Estimation of nuclei}

By Giemsa staining it was shown that large yeast protoplasts had one or exceptionally two nuclei (Fig. 5). In contrast, 88 to $92 \%$ of the small protoplasts contained no nuclei (Fig. 6). Limitations in the separating technique resulted in the presence of large nucleated protoplasts in the fraction of anucleated protoplasts.

Results obtained by nuclear staining of small protoplasts were in agreement with observation of ultra-thin sections and freeze-etching replicas (see below).

\section{Growth of anucleated protoplasts}

The fraction of anucleated protoplasts was divided into three parts: one was inoculated in liquid Ni medium, the second was inoculated in liquid malt extract medium (osmotically stabilized), and the third was inoculated on the surface of Ni agar. These protoplasts were observed for 5 days by means of a phase-contrast microscope. Most freshly released anucleated protoplasts had a homogenous appearance (Fig. 2, 4) but after $24 \mathrm{~h}$ of cultivation on the surface of agar they were found to contain one or more small vacuoles (Fig. 7). Protoplasts cultivated in liquid and on solid media behaved similarly, the size and shape of these protoplasts being essentially unchanged, i.e. most of them failed to grow. About $8.5 \%$ of protoplasts were capable of growing and these were believed to be the nucleated protoplasts contaminating the fraction of anucleated protoplasts.

The protoplasts of the nucleated fraction started to grow within $2 \mathrm{~h}$ of inoculation, both in liquid and on solid media (Fig. 8). Almost all grew $(96 \%)$, but they died after 24 to $48 \mathrm{~h}$ of cultivation.

\section{Synthesis of the fibrillar wall component by anucleated protoplasts}

Since the basic aim of this work was to establish whether anucleated yeast protoplasts could synthesize glucan fibrils on their surfaces, formation of the fibrillar wall component in yeast protoplasts was studied by electron microscopy of shadowed preparations. This method provided a reliable means for the quantitative evaluation of fibril formation since protoplasts with or without fibrillar nets were equally firmly affixed on to grids and could not be removed by the washings. Thus the presence or absence of fibrils could be ascertained for each protoplast.

Most of the anucleated protoplasts (88\%) did not form fibrils (Fig. 9). The fibrillar nets were observed only in protoplasts which were markedly larger than the others, and these occurred infrequently ( $12 \%$ ) in the culture. 

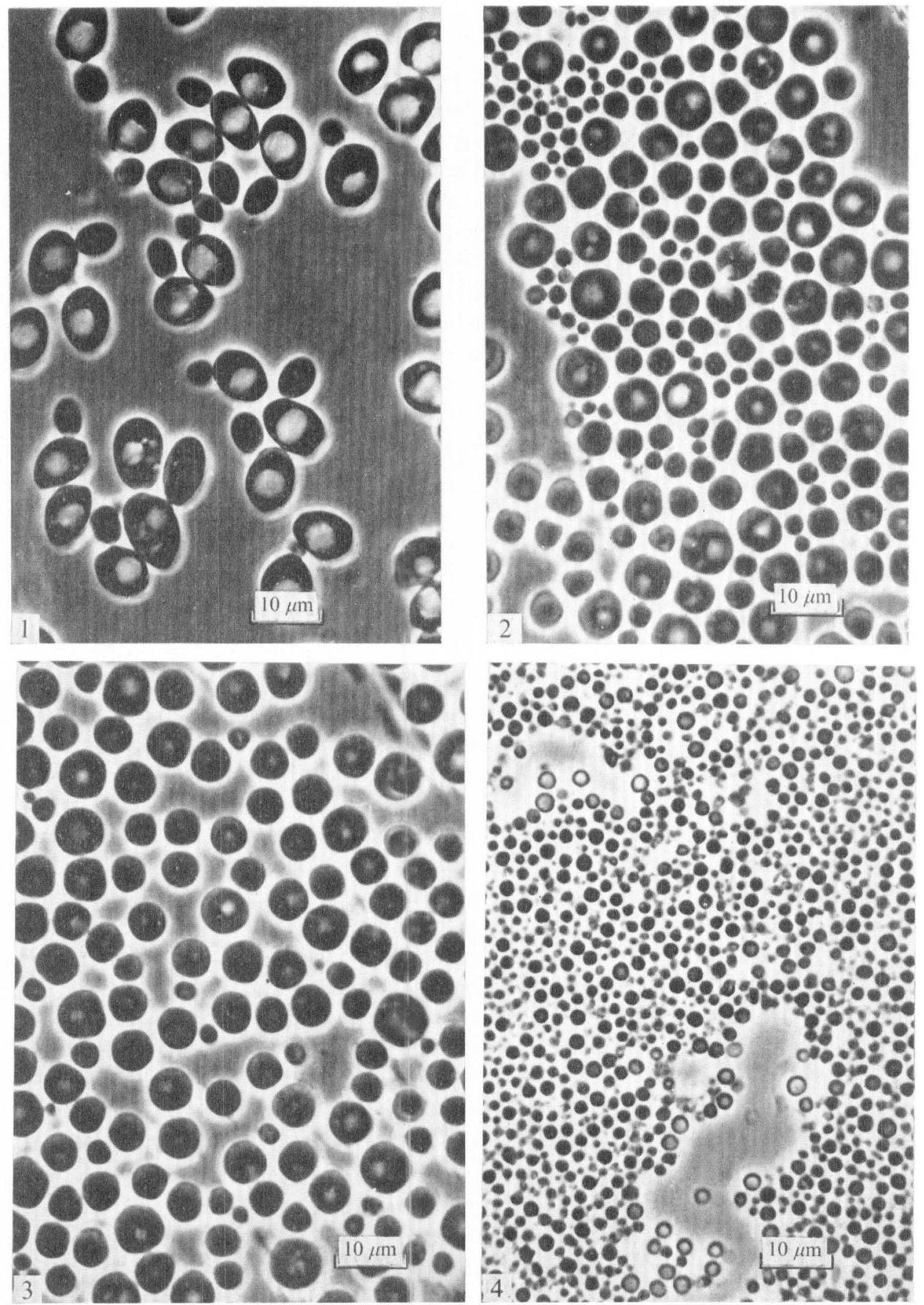

Fig. I. Saccharomyces cerevisiae near the end of the log phase as used for the preparation of anucleated protoplasts.

Fig. 2. A mixture of large and small protoplasts of Saccharomyces cerevisiae prepared on a shaker by a $3 \mathrm{~h}$ digestion with snail enzymes in $0.6 \mathrm{M}-\mathrm{KCl}(\mathrm{pH} 5.5)$ at $28{ }^{\circ} \mathrm{C}$.

Fig. 3. A fraction of large (nucleated) protoplasts of Saccharomyces cerevisiae.

Fig. 4. A fraction of small (anucleated) protoplasts of Saccharomyces cerevisiae. 

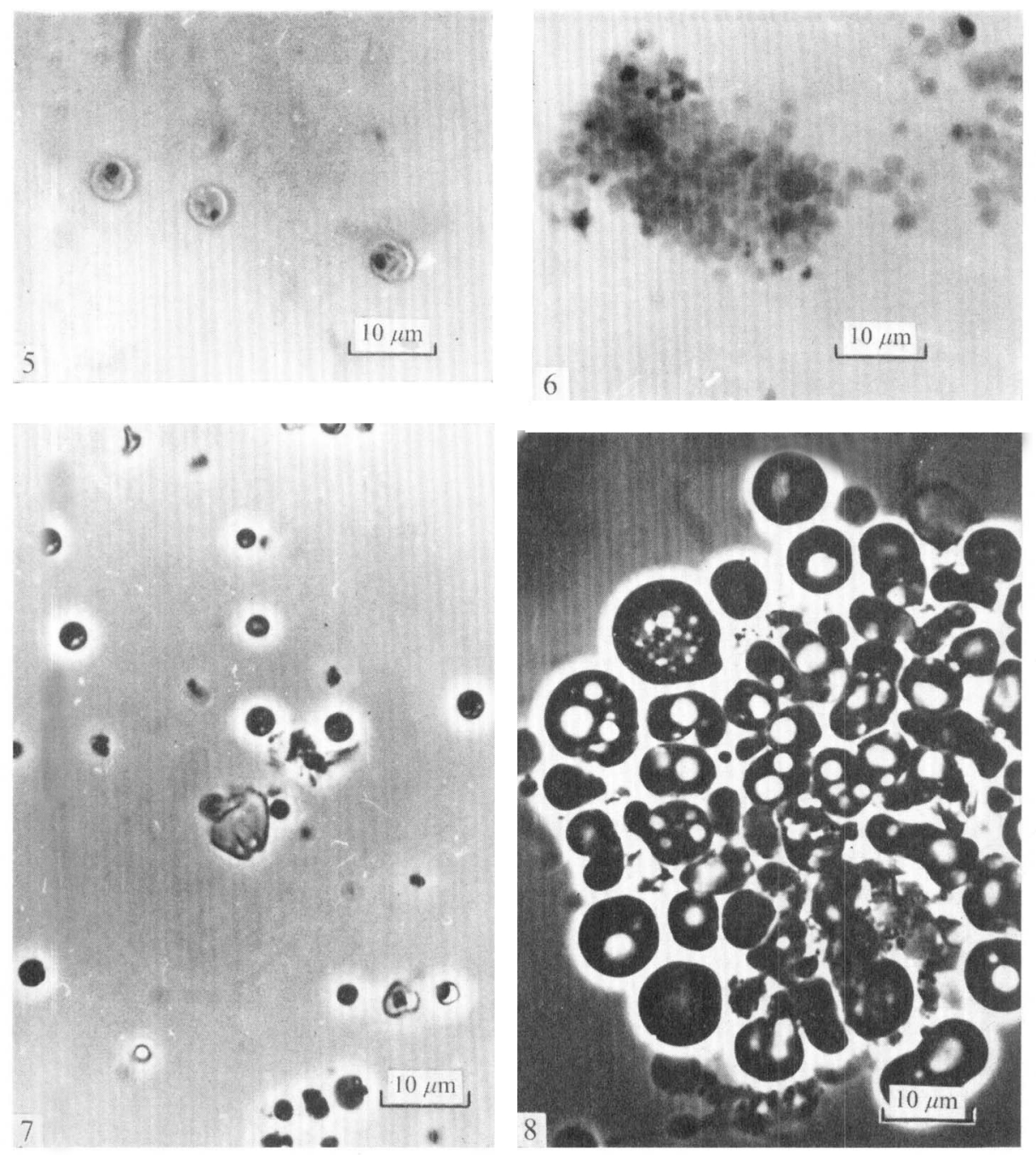

Fig. 5. Large protoplasts of Saccharomyces cerevisiae stained by the Giemsa method. One nucleus is visible inside each protoplast.

Fig. 6. Small protoplasts of Saccharomyces cerevisiae stained by the Giemsa method. Most of the protoplasts do not contain nuclei.

Fig. 7. A fraction of anucleated protoplasts of Saccharomyces cerevisiae cultivated on the surface of Ni agar for $24 \mathrm{~h}$. Some protoplasts contain one or more small vacuoles. No growth was observed. For comparison of size see the wall in the middle of the picture.

Fig. 8. A fraction of nucleated protoplasts of Saccharomyces cerevisiae cultivated in liquid medium for $6 \mathrm{~h}$. Most of them grow either spherically or cylindrically.

These findings are strikingly different from the results generally obtained with nucleated protoplasts of Saccharomyces cerevisiae in which, in liquid media, $98 \%$ of protoplasts synthesize the fibrillar wall component within 2 to $3 \mathrm{~h}$ of cultivation (Fig. 10).

\section{Ultrastructure of protoplasts}

Ultra-thin sectioning and freeze-etching were employed to determine any changes in the ultrastructure of anucleated protoplasts in comparison with the normal nucleated ones. 


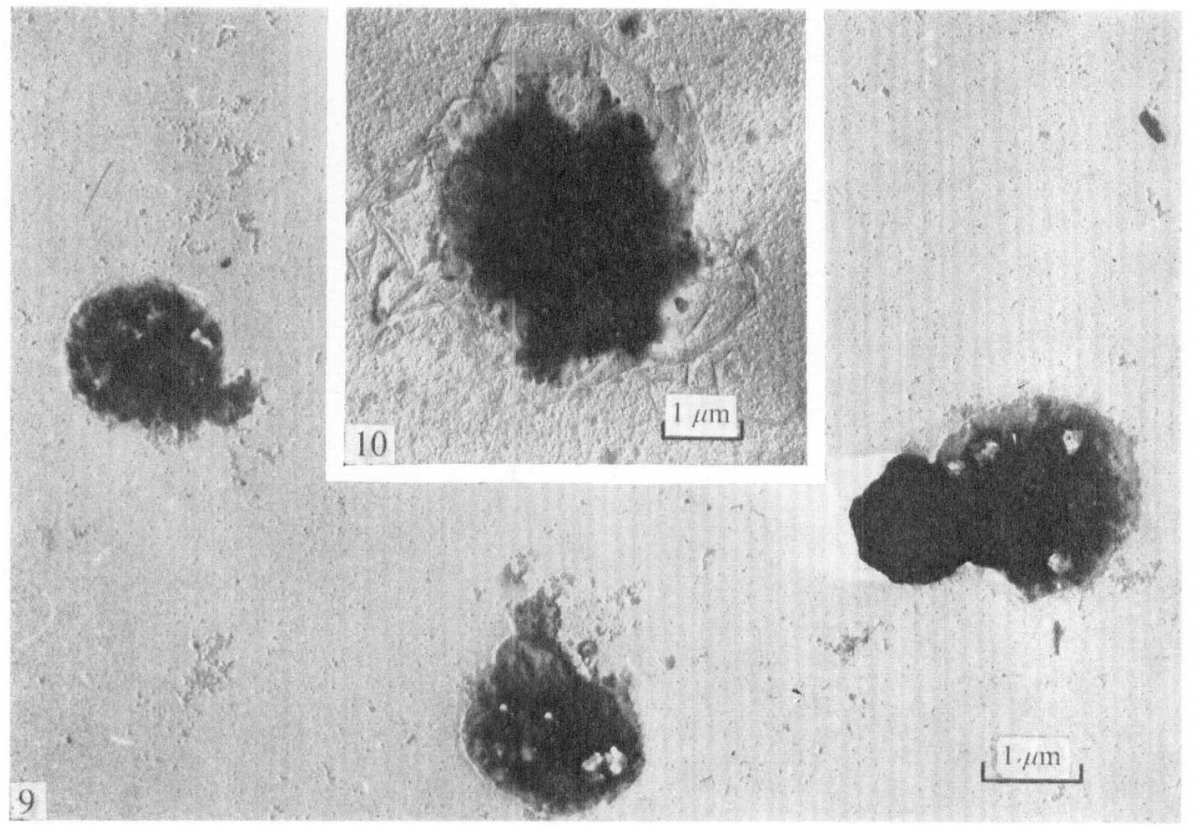

Fig. 9. An electron micrograph of the metal-shadowed preparation of a fraction of anucleated protoplasts of Saccharomyces cerevisiae, after $24 \mathrm{~h}$ of cultivation in liquid nutrient medium. No fibrils are visible on the surfaces of the protoplasts.

Fig. 10. An electron micrograph of the metal-shadowed preparation of a nucleated protoplast of Saccharomyces cerevisiae after $24 \mathrm{~h}$ of cultivation in liquid nutrient medium. Fibrils are clearly visible.

In both types, the normal endoplasmic reticulum, mitochondria and vacuoles were observed (Fig. I I). Thus, except for the nucleus, the principal characteristics of anucleated protoplasts were considered to be the same as those of nucleated ones, though the extent of quantitative relations between different cell organelles could not be estimated. The plasma membrane on freeze-etching replicas (Fig. I2) and on metal-shadowed preparations (Fig. I3) showed particles Io $\mathrm{nm}$ in diameter like those found on nucleated protoplasts (Streiblová, I968; Nečas, Kopecká \& Brichta, I969) as well as in whole organisms (Moor \& Mühlethaler, I963).

\section{DISCUSSION}

Preparation of protoplasts from a large culture of the log-phase Saccharomyces cerevisiae enabled us to obtain, as well as a population of large protoplasts, a fraction of small protoplasts of which about $90 \%$ did not contain nuclei. In most cases small protoplasts probably originated from the buds of dividing cells. This assumption is supported by the fact that they appeared soon after addition of snail enzymes to the medium. The first small protoplasts were detected within 5 to $10 \mathrm{~min}$, at which time the walls of the mother yeasts had not been lysed and protoplasts of normal size had usually not arisen. It is known that the walls of young organisms are more susceptible to lytic enzymes than are those of older ones (Eddy \& Williamson, 1957; Bacon et al. 1970; Brown, I971). In populations of yeast dividing asynchronously, at any given moment a certain proportion of organisms with small buds lacking nuclei can be found. The protoplast arising from such a bud is probably separated from the mother yeast protoplast by surface tension forces. Apparently, the 

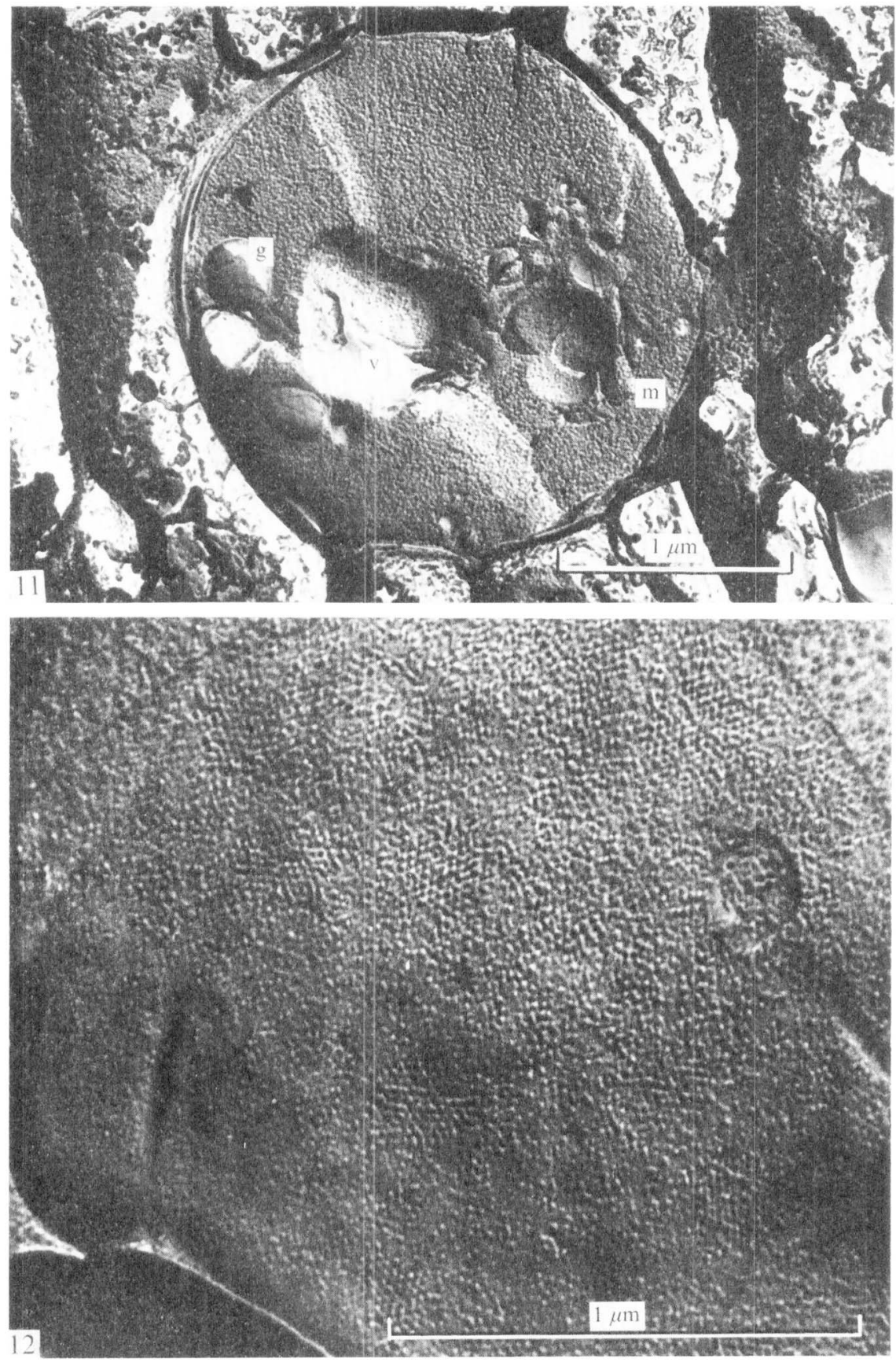

Fig. 11. An electron micrograph of a freeze-etched anucleated protoplast of Saccharomyces cerevisiae. The cytoplasm contains a vacuole, lipid granules, small vesicles and mitochondria. $v$, Vacuole; $m$, mitochondria; $g$, lipid granule.

Fig. 12. An electron micrograph of a freeze-etched anucleated protoplast of Saccharomyces cerevisiae; the plasma-membrane particles have an average diameter of $10 \mathrm{~nm}$. 


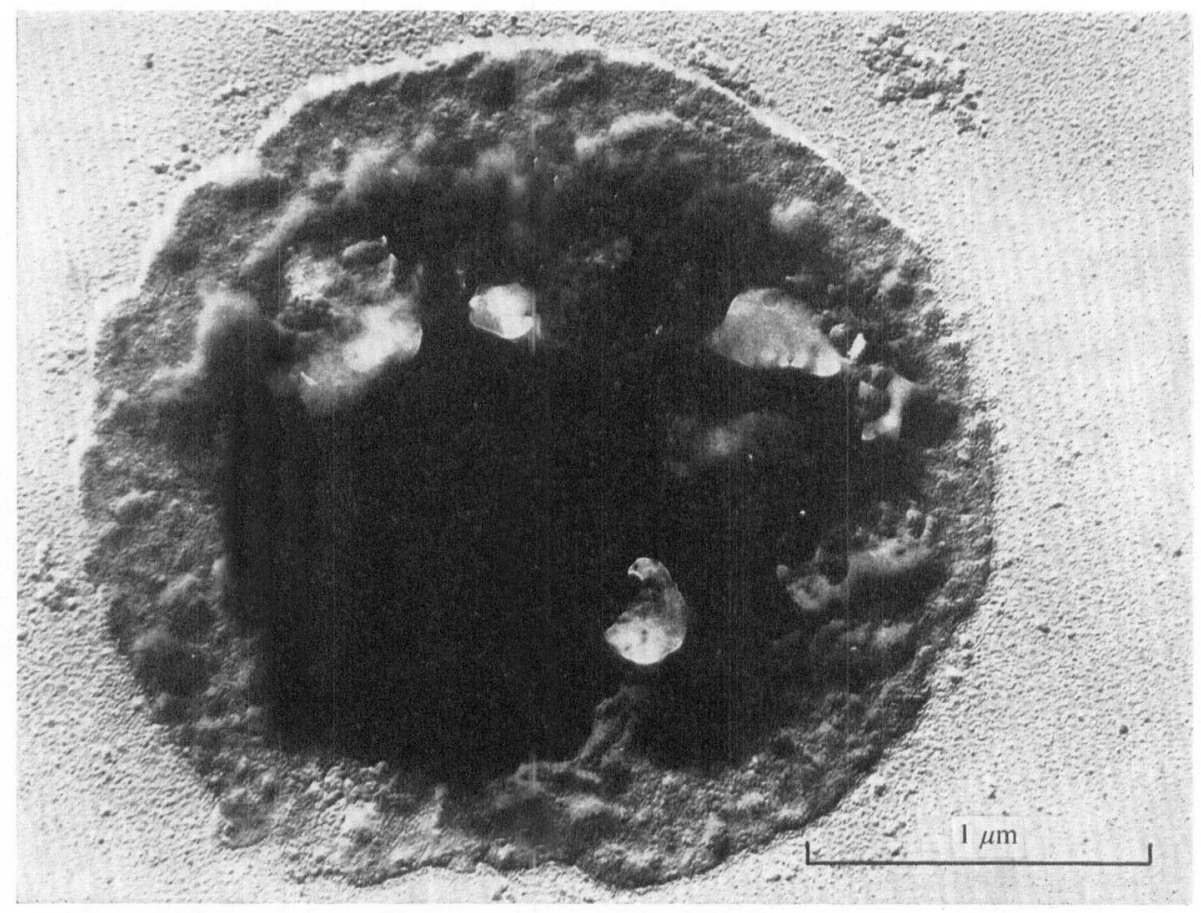

Fig. 13. An electron micrograph of the metal-shadowed preparation of an anucleated protoplast of Saccharomyces cerevisiae after 5 days of cultivation in liquid nutrient medium. No fibrils are formed by this protoplast. On the plasma membrane $10 \mathrm{~nm}$ diameter particles are visible.

different physical properties of the cytoplasm of the bud compared to that in the mother cell play a role in the separation process. This process may be similar to the mechanism of formation of protoplasts of different sizes in syncitial moulds (Gabriel, I968).

There may exist an additional mechanism of formation of anucleated protoplasts: fragmentation of large, complete protoplasts, as was demonstrated during the preparation of protoplasts by mechanical pressure (Nečas, 1955).

As expected, the anucleated protoplasts of yeast cells would not grow owing to the absence of protein synthesis. This is in agreement with the results reported by Nečas (1956) on the behaviour of anucleated plasma droplets in the yeast, as well as with the general concept on the role of the nucleus. However, it was also expected that anucleated protoplasts, though incapable of forming the complete wall, would synthesize the fibrillar component because protein synthesis is not required for the latter (Nečas et al. 1968). This assumption proved to be incorrect because no wall component was detected on anucleated protoplasts.

The evidence against protein synthesis being necessary for fibrillar formation is based on the insensitivity of the latter to cycloheximide inhibition (Nečas et al. I968). It has been reported that the blockage due to cycloheximide is not complete (about $97 \%$ ), the residual protein synthesis being associated with $77 \mathrm{~S}$ ribosomes, i.e. the ribosomes of mitochondria (Siegel \& Sisler, 1964). Nevertheless, the formation of the glucan fibrillar component in yeast by mitochondrial protein synthesis seems to be unlikely.

Conceivably in small anucleated protoplasts some other cellular structures directly or indirectly related to fibril formation might also be missing. However, in small protoplasts 
examined by ultra-thin sectioning and freeze-etching, all principal cell structures were found (the endoplasmic reticulum, mitochondria and vacuoles).

Results from freeze-etching replicas also appeared to exclude the possibility that the inability of small protoplasts to form fibrils was caused by damage to the plasma membrane, because the surface of the plasma membrane of small protoplasts did not differ from that in nucleated protoplasts. The morphology and distribution of plasma-membrane particles, which some authors (Moor \& Mühlethaler, 1963; Frey-Wyssling, I969; Barnet \& Preston, I970) reported as sites of wall glucan synthesis, were unchanged in small protoplasts compared with the picture obtained in nucleated protoplasts.

Paradoxically, although young buds synthesize the wall much more actively than the mother yeasts (Johnson \& Gibson, I966; Johnson, I968), the protoplasts from the buds were totally incapable of forming glucan fibrils, whereas those derived from the mother yeasts retained this capacity. The reason for this behaviour is not clear.

The authors thank Professor S. Bartnicki-Garcia for critically reading the manuscript.

Note added at proof. Recent time-lapse cinematographical observation proved that small protoplasts originated from the buds of yeasts.

\section{REFERENCES}

Bacon, J. S., Gordon, A. H., Jones, D., TAylor, I. F. \& Webley, D. M. (I970). The separation of $\beta$-glucanases produced by Cytophaga johnsonii and their role in the lysis of yeast cell walls. Biochemical Journal I20, $67-68$.

Barnet, J. R. \& Preston, R. D. (1970). Arrays of granules associated with the plasmalemma in swarmers of Cladophora. Annals of Botany 34, I01 I-IO17.

Brown, J. P. (1971). Susceptibility of the cell walls of some yeasts to lysis by enzymes of Helix pomatia. Canadian Journal of Microbiology $\mathbf{1 7}, 205-208$.

EdDy, A. A. \& Williamson, D. H. (1957). A method of isolating protoplasts from yeasts. Nature, London I79, I 252-I 253 .

Farkaš, V., Svoboda, A. \& Bauer, S̆. (1969). Inhibitory effect of 2-deoxy-D-glucose on the formation of the cell wall in yeast protoplasts. Journal of Bacteriology $98,744-748$.

Frey-WyssLing, A. (1969). The ultrastructure and biogenesis of native cellulose. In Process in the Chemistry of Organic Natural Compounds, vol. 27, pp. I-26. Edited by L. Zechmeister. Vienna, New York: Springer Verlag.

Gabriel, M. (I968). Formation and regeneration of protoplasts in the mould Rhizopus nigricans. Folia microbiologica, Praha 13, 23 I-235.

JoHnson, B. F. (1968). Lysis of yeast cell walls induced by 2-deoxyglucose at their sites of glucan synthesis. Journal of Bacteriology 95, I169-1 172.

Johnson, B. F. \& Gibson, E. J. (i966). Autoradiographic analysis of regional cell wall growth of yeasts. Experimental Cell Research 4I, 580-591.

KopeCKÁ, M., ČTVRTNíČEK, O. \& NeČAS, O. (I965). Formation and properties of fibrillar network formed in yeast protoplasts as the first step of biosynthesis of the cell wall. In Symposium über Hefe-Protoplasten, pp. 73-75. Edited by R. Müller. Berlin: Akademie Verlag.

KopeckÁ, M., NeČAs, O. \& Svoboda, A. (1968). Structure and formation of the fibrillar component of the growing cell wall in yeast protoplasts. In Yeast Protoplasts. Proceedings of the International Symposium, pp. 197-201. Edited by O. Nečas and A. Svoboda. Brno: J. E. Purkyně University Press.

MACY, J. M. \& Miller, M. W. (I97I). Endomyces tetrasperma, sp.n. Journal of Bacteriology 105, 637-645.

MoOR, H. \& MüHlethaler, K. (1963). Fine structure in frozen-etched yeast cells. Journal of Cell Biology I7, 609-628.

NEČAS, O. (1955). The vitality of cell fragments of yeasts. II. Developmental changes in plasmatic droplets. Folia Biologica, Praha 1, I04-II2.

NEČAs, O. (I956). Vitality of cell fragments of yeasts. IV. Relation of the nucleus to growth ability. Folia biologica, Praha 2, 29-35. 
NEČAS, O. (1965). Mechanism of regeneration of yeast protoplasts. II. Formation of the cell wall de novo. Folia biologica, Praha I1, 97-102.

NEČAS, O., KOPECKÁ, M. \& BRICHTA, J. (1969). Interpretation of surface structures in frozen-etched protoplasts of yeast. Experimental Cell Research 58, $4 \mathrm{I}$ I-419.

NeČAS, O., Svoboda, A. \& KopeCKÁ, M. (1968). The effect of cycloheximide (actidione) on cell wall synthesis in yeast protoplasts. Experimental Cell Research 53, 29 I-293.

SIEGEL, M. R. \& SisLER, H. D. (I964). Site of action of cycloheximide in cells of Saccharomyces pastorianus. Biochimica et biophysica acta 87, 70-82.

Streibloví, E. (1968). Surface structures in yeast protoplasts. Journal of Bacteriology 95, 700-707. 